\title{
Relative influence of soil chemistry and topography on soil available micronutrients by structural equation modeling
}

\author{
Hongfen Zhu' ${ }^{1}$, Ying Zhao ${ }^{2}$, Feng Nan ${ }^{1}$, Yonghong Duan ${ }^{1}$, Rutian $\mathrm{Bi}^{1 *}$
}

${ }^{1}$ College of Resource and Environment, Shanxi Agricultural University, 1\# South Mingxian Road, Taigu, Shanxi 030801, P. R. China.

${ }^{2}$ College of Resource and Environment Science,Northwest Agriculture and Forestry University, Yangling, Shaanxi 712100, P. R. China. *Corresponding author: sxndbrt@163.com

\begin{abstract}
Soil chemical and topographic properties are two important factors influencing available micronutrient distribution of soil in the horizontal dimension. The objective of this study was to explore the relative influence of soil chemistry (including soil $\mathrm{pH}$, soil organic matter, total nitrogen, available phosphorus, and available potassium) and topography (including elevation, slope, aspect, and wetness index) on the availability of micronutrients ( $\mathrm{Fe}$, $\mathrm{Mn}, \mathrm{Cu}, \mathrm{Zn}$, and B) using structural equation modeling (SEM) at the watershed scale. To do this, levels of soil micronutrients, $\mathrm{pH}$, soil organic matter, total nitrogen, available phosphorus, available potassium, and topographic factors were measured at 523 sampling points of Fanshi County on the Chinese Loess Plateau, and the spatial distribution of soil available micronutrients were analyzed by geostatistical method. The results showed that topography had both direct effects and indirect effect on some soil micronutrients, while the indirect effect indicated effects from topography on soil chemistry and then further on micronutrient concentration. Soil chemistry had direct effects on levels of all soil micronutrients, and topography had direct effects on levels of all micronutrients except for $\mathrm{Cu}$ and $\mathrm{B}$, and indirect effects on $\mathrm{Fe}, \mathrm{Zn}$, and $\mathrm{B}$. The direct effect of soil chemistry on Fe levels was greater than the total effects (including both direct and indirect) of topography. Topography had a stronger direct effect on Mn than soil chemistry, and topography had less direct but stronger total effects on $\mathrm{Zn}$ than soil chemistry. Soil chemistry directly influenced both $\mathrm{Cu}$ and B, but topography only influenced B in an indirect manner. The semivariance indicated that the micronutrients had moderate spatial dependency except for $\mathrm{B}$ which had weak spatial dependency. Within the spatial distribution of the micronutrients, there was a zone in the middle of the watershed with lower values than in the northern and southern areas for Fe, Mn, Zn, and B, which were related to the characteristics of topography and soil chemistry. These results may guide the management of soil micronutrients of the Chinese Loess Plateau and other similar regions in the world.
\end{abstract}

Keywords: Structural equation modeling (SEM), spatial distribution,standardized path coefficients (SPCs), latent variables, manifest variables 


\section{Introduction}

The availability of soil micronutrients, including iron $(\mathrm{Fe})$, manganese $(\mathrm{Mn})$, copper $(\mathrm{Cu})$, zinc $(\mathrm{Zn})$, and boron (B), plays an important role in crop growth, development, quality, and can eventually impact human health (Farooq et al., 2012). The levels of available micronutrientsin topsoil vary spatially under different types of parent material, vegetation,topography, climate,fertilizer application, and land use types (Wang et al., 2008). Thus, improved understanding of the dynamic variationinthese micronutrients and the factors that contribute to their levels in the soil isan important issue.

The influences of soil and topographic properties on topsoil available micronutrients are wildly recognized. Soil properties can affect available micronutrients distribution, including soil organic matter (Rais et al., 2006), pH (Sims and Patrick, 1978), moisture regime (Katyal and Sharma, 1991), and available P (Shuman, 1988). Topography also influences the availability of micronutrients (Wang et al., 2008; Yi et al., 2012). To determine the relationships between the micronutrients and influencing factors, descriptive methods of regression or correlation analysis have been usually used. However, these methods consider the measured variable only (Arhonditsis et al., 2006), limiting assessment of complex influences of soil chemistry and topography on the micronutrients. Better understanding on the factors altering micronutrient availability may be possible if a model can include variables that are not measured but also affect the distribution of micronutrients.

Structural equation modeling (SEM) is a multivariate statistical method used to examine the intertwined correlation among manifest and latent variables (DelgadoBaquerizo et al., 2015). In this model, manifest variables are measured directly, while latent variables are not. Latent variables are predictedfrom the manifest variables, allowing comprehensive understanding of both measurement unreliability and the relationships between latent variables (Stephenson et al., 2006). For example, Beaumelle (2016) determined the bioavailability of soil cadmium, lead, and zinc by the unmeasured variable reflected by several observed variables. Liu (2016) examined the relationship between two latent variables of "spec", which was explained by the observed variables of spectral reflectance, and "attrib", which was made up of soil salt and moisture in the surface and subsurface soil. Angelini (2016) mapped seven key soil properties in the Argentinian Pampas based on the SEM theory. Therefore, when the observed properties are unable to accurately represent the latent variables, SEM is a reasonable alternative. Additionally, SEMcan separate direct and indirect effects. For instance, topography can have both direct and indirect effects on soil micronutrients distribution. It can affect micronutrients contents directly, and can influence soil chemical properties, such as organic matteror $\mathrm{pH}$, and further exert on the micronutrients indirectly.

The soil on the Chinese Loess Plateau is considered the most highly erodible soil in the world (Tian and Huang, 2000), and the available soil micronutrient contents are often insufficient for plant growth. The spatial distribution of micronutrients at the watershedmay be affected by the soil chemical and topographic properties. Therefore, the objective of this study was to assess the relative influences of the latent variables, soil chemistry and topography, on available micronutrients and disentangle the complex relationships between these factors using SEM at the watershed scale on the Chinese Loess Plateau.

\section{Materials and Methods}

\subsection{Study site description}

A small watershed $\left(39^{\circ} 00^{\prime}\right.$ to $39^{\circ} 30^{\prime} \mathrm{N}$ and $113^{\circ} 09^{\prime}$ to $114^{\circ} 00^{\prime} \mathrm{E}$ ) with an area of $2,400 \mathrm{~km}^{2}$ was selected 
on the northeast of the Chinese Loess Plateau $\left(33^{\circ} 35^{\prime}\right.$ to $41^{\circ} 10^{\prime} \mathrm{N}, 100^{\circ} 22^{\prime}$ to $114^{\circ} 40^{\prime} \mathrm{E}$ ), Fanshi County, Shanxi Province, China (Figure 1).The Hutuo River originates in the northeast and runs across from the east to the west of this region.

(a) China

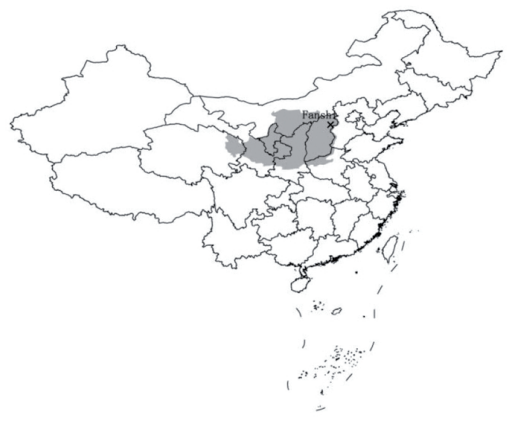

(b) Loess Plateau

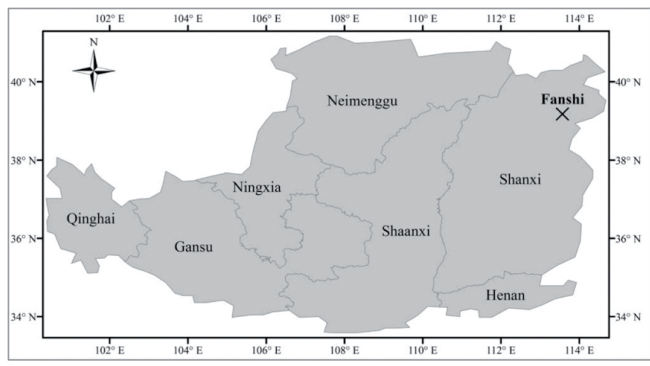

(c) The study site of Fanshi

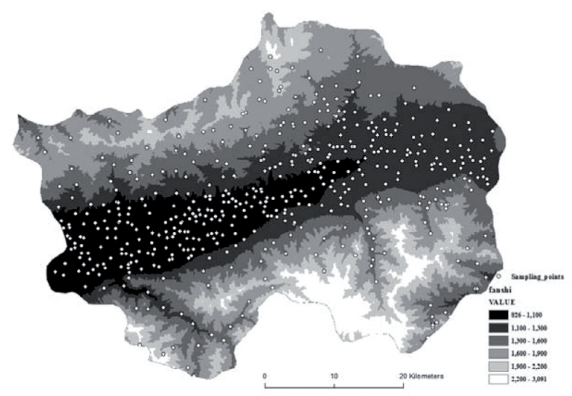

Figure 1. Geographic location of the study site and soil sampling locations, (a) China, (b) the Loess Plateau, and (c) the study site of Fanshi.

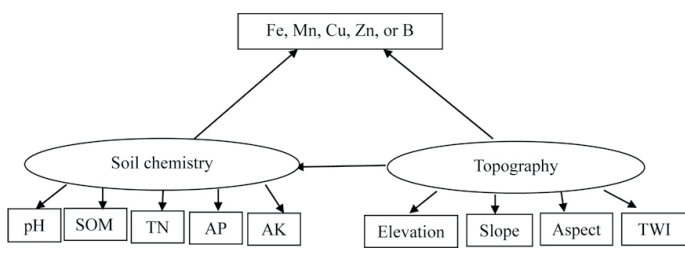

Figure 2. The conceptual framework of the structural equation modeling (SEM) showingthe relationships between endogenous variables (soil available micronutrients) and exogenous latent variables (soil chemistry and topography). The solid arrows represent the direct pathway of the influence of one variable on another. The observed variables are in the rectangle and the latent variables are in the ellipse.

The research area has a temperate continental climate with a mean annual temperature of $6.3{ }^{\circ} \mathrm{C}$, precipitation of $400 \mathrm{~mm}$, and frost-free period of 130 days. This area is characterized by eroded ridges and different sized hill slopes. The dominant crop is cereal.The elevations of the research area range from 826 to 3091 $\mathrm{m}$ and generally decrease from northeast to southwest. According to the FAO-90 soil classification system, the main soil types are Calcaric Cambisol, and Calcaric Regosols (Nachtergaele et al., 2008), the typical soils in Shanxi Province, China. The textures of this area are loam and sandy loam, and the $\mathrm{pH}$ varies from 7.2 to 8.6 .

\subsection{Data collection}

A total of 523 points were sampled at Fanshi County. At each location, one sample of $0-20 \mathrm{~cm}$ soil layer was collected. The samples were air-dried, ground, and sieved through a sieve of $1 \mathrm{~mm}$. The available iron $(\mathrm{Fe})$, manganese $(\mathrm{Mn})$, copper $(\mathrm{Cu})$, and zinc (Zn) were extracted by DTPA, and available boron (B) was extracted by the hot water extraction method (Environmental Monitoring of China, 1992). These available micronutrients were measured using atomic 
adsorption spectrometry. Soil $\mathrm{pH}$ was measured using acombination electrode. SOM content was determined using the wet oxidation method of Walkley and Black, and TN content was determined according to Kjeldahl method. The AP content was measured by the method of Olsen extraction. AK was extracted by ammonium acetate extraction and analyzed by flame photometer (Bao, 2008).

The digital elevation model (DEM) with $30 \mathrm{~m}$ resolution of the small watershed was downloaded from the website: http://www.gscloud.cn/sources/?cdataid $=302 \&$ pdataid $=10$. The digital elevation was used to extract topographic indices including slope gradients, aspect, and topographic wetness index using ArcGIS 10.1 (ESRI Inc.).

\subsection{Structural equation modeling}

Structural equation modeling is a multivariate statistical methodology to estimate the relative relationships between exploratory variables (Kline, 1998). It includes a structural model and measurement model. The structural model reveals the relationships between exogenous variables (i.e., "soil chemistry" and "topography") and endogenous variables (i.e., Fe, Mn, $\mathrm{Cu}, \mathrm{Zn}$, or B). The exogenous variable is the variable to be regressed and the endogenous variable is the latent variable to be predicted. The variables with quotation marks arethe latent variables. The structural model is defined as

$\eta=\Gamma \xi+\omega$

where, $\eta$ is an endogenous variable, $\xi$ is an exogenous variable, and $\Gamma$ is the matrix of regression coefficients between $\eta$ and $\xi$. $\omega$ is a vector of the structural error. The measurement model is described as

$\mathrm{X}=\Lambda_{\mathrm{x}} \xi+\delta$

$\mathrm{Y}=\Lambda_{\mathrm{y}} \eta+\varepsilon$

where, $\mathrm{X}$ is a vector of the observed measurements (i.e., pH, SOM, TN, AP, AK, elevation, slope, aspect, and TWI) of the exogenous variables $\xi$ (i.e., "soil chemistry" and "topography"), $\mathrm{Y}$ is a vector of the observed measurements (i.e., $\mathrm{Fe}$ ) of the endogenous variables $\eta, \delta$ is a vector of the measurement error for $\mathrm{X}, \varepsilon$ is a vector of the measurement error for $\mathrm{Y}, \Lambda_{\mathrm{x}}$ is a matrix of factor loading between $X$ and $\xi$, and $\Lambda_{y}$ is a matrix of factor loading between $Y$ and $\eta$. For example, the matrices for the exogenous variable measurement model of $\mathrm{Fe}$ are

$$
\mathrm{X}=\left[\begin{array}{l}
x_{1} \\
x_{2} \\
x_{3} \\
x_{4} \\
x_{5} \\
x_{6} \\
x_{7} \\
x_{8} \\
x_{9}
\end{array}\right]=\left[\begin{array}{l}
p H \\
S O M \\
T N \\
A P \\
A K \\
\text { Elevation } \\
\text { Slope } \\
\text { Aspect } \\
\text { TWI }
\end{array}\right] \Lambda_{\mathrm{x}}=\left[\begin{array}{ll}
\lambda_{1} & 0 \\
\lambda_{2} & 0 \\
\lambda_{3} & 0 \\
\lambda_{4} & 0 \\
\lambda_{5} & 0 \\
0 & \lambda_{6} \\
0 & \lambda_{7} \\
0 & \lambda_{8} \\
0 & \lambda_{9}
\end{array}\right] \quad \xi=\left[\begin{array}{l}
\xi_{1} \\
\xi_{2}
\end{array}\right]=\left[\begin{array}{c}
\text { Soil chemistry } \\
\text { Topography }
\end{array}\right] \quad \delta=\left[\begin{array}{l}
\delta_{1} \\
\delta_{2} \\
\delta_{3} \\
\delta_{4} \\
\delta_{5} \\
\delta_{6} \\
\delta_{7} \\
\delta_{8} \\
\delta_{9}
\end{array}\right]
$$


The estimate of coefficients $\left(\lambda_{i}\right)$ in the matrix of $\Lambda_{x}$ can be standardized and described as standardized path coefficients (SPCs).

\subsection{Data analysis}

The classical statistics and Pearson correlation analysis were calculated using the IBM SPSS 19.0 (SPSS Inc.).The spatial patterns of available micronutrients were determined by the geostatistical analysis of ArcGIS 10.1 (ESRI Inc.).

All the observed variables were normalized between 0 and 1 to minimize the variation of each observed variable. A conceptual SEM was established based on previous studies (Hu and Si, 2014; Zhu et al., 2014). This model consists of twolatent variables: topography and soil chemistry (Figure 2). The latent variable of topography was represented by topographic parameters such as elevation, slope, wetness index, and aspect. The latent variable of soil chemistry was represented by the observed variables of $\mathrm{pH}, \mathrm{SOM}, \mathrm{TN}, \mathrm{AP}$, and AK. Different SEMs were established based on each measured micronutrient including $\mathrm{Fe}, \mathrm{Mn}, \mathrm{Cu}, \mathrm{Zn}$, and $\mathrm{B}$. The detailed model was developed by specify- ing the pathways in these models. Finally, the parameters of these SEMs were fitted using the method of maximum likelihood estimation, which was achieved by AMOS 17.0 for windows (SPSS Inc.).

\section{Results}

\subsection{Descriptive statistical analysis}

Descriptive statistics for micronutrients, soil chemical parameters, and topographyare listed in Table 1 . The mean values of available $\mathrm{Fe}, \mathrm{Mn}, \mathrm{Cu}, \mathrm{Zn}$, and $\mathrm{B}$ were $9.0,9.3,1.6,1.0$, and $0.6 \mathrm{mg} \mathrm{kg}^{-1}$, respectively. According to the classification standard of available micronutrients in Shanxi Province (Table 2), these values were at a medium level except for $\mathrm{Cu}$, which was present at high level. The mean values of $\mathrm{pH}, \mathrm{SOM}$, TN, AP, and AK were 8.1, $12.7 \mathrm{~g} \mathrm{~kg}^{-1}, 0.7 \mathrm{~g} \mathrm{~kg}^{-1}, 9.6$ $\mathrm{mg} \mathrm{kg}{ }^{-1}$, and $117.8 \mathrm{mg} \mathrm{kg}^{-1}$, respectively. The mean values of elevation, slope, aspect, and TWI were $1173.2 \mathrm{~m}, 5.7^{\circ}, 188.1^{\circ}$, and 1.0 , respectively.

The ranges of AK, elevation, and aspect were higher, and must to be normalized to minimize the variations with other observes.

Table 1. Classical statistics of soil micronutrients, soil chemical and topographic properties in Fanshi County on the Chinese Loess Plateau.

\begin{tabular}{|c|c|c|c|c|c|c|c|c|c|}
\hline $\begin{array}{c}\text { Latent } \\
\text { variables }\end{array}$ & Observed variables & Mean & Max & Min & Medium & $\begin{array}{c}\text { Upper } \\
\text { quartile }\end{array}$ & $\begin{array}{c}\text { Lower } \\
\text { quartile }\end{array}$ & Skewness & Kurtosis \\
\hline \multirow{5}{*}{ 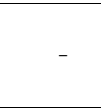 } & $\mathrm{Fe}\left(\mathrm{mg} \mathrm{kg}^{-1}\right)$ & 8.98 & 30.20 & 2.60 & 7.60 & 5.70 & 10.70 & 1.8 & 3.5 \\
\hline & $\mathrm{Mn}\left(\mathrm{mg} \mathrm{kg}^{-1}\right)$ & 9.25 & 26.80 & 1.30 & 8.40 & 5.00 & 12.90 & 0.8 & 0.2 \\
\hline & $\mathrm{Cu}\left(\mathrm{mg} \mathrm{kg}^{-1}\right)$ & 1.62 & 3.60 & 0.29 & 1.58 & 1.10 & 2.01 & 0.5 & -0.1 \\
\hline & $\mathrm{Zn}\left(\mathrm{mg} \mathrm{kg}^{-1}\right)$ & 0.97 & 3.42 & 0.03 & 0.82 & 0.44 & 1.39 & 1.0 & 0.3 \\
\hline & $\mathrm{B}\left(\mathrm{mg} \mathrm{kg}^{-1}\right)$ & 0.56 & 1.97 & 0.01 & 0.48 & 0.30 & 0.73 & 1.2 & 1.6 \\
\hline \multirow{5}{*}{$\begin{array}{l}\text { Soil } \\
\text { chemical } \\
\text { properties }\end{array}$} & $\mathrm{pH}$ & 8.11 & 8.60 & 7.20 & 8.10 & 8.00 & 8.20 & -1.4 & 4.2 \\
\hline & SOM $\left(\mathrm{g} \mathrm{kg}^{-1}\right)$ & 12.70 & 39.90 & 2.00 & 11.60 & 8.90 & 15.30 & 1.3 & 2.5 \\
\hline & $\mathrm{TN}\left(\mathrm{g} \mathrm{kg}^{-1}\right)$ & 0.67 & 1.94 & 0.10 & 0.60 & 0.47 & 0.81 & 1.0 & 1.2 \\
\hline & $\mathrm{AP}\left(\mathrm{mg} \mathrm{kg}^{-1}\right)$ & 9.59 & 42.00 & 0.20 & 6.60 & 3.70 & 13.20 & 1.5 & 1.7 \\
\hline & $\mathrm{AK}\left(\mathrm{mg} \mathrm{kg}^{-1}\right)$ & 117.83 & 328.00 & 27.00 & 102.00 & 79.00 & 137.00 & 1.7 & 2.7 \\
\hline \multirow{4}{*}{$\begin{array}{l}\text { Topographic } \\
\text { properties }\end{array}$} & Elevation (m) & 1173.15 & 2183.00 & 864.00 & 1113.00 & 977.00 & 1268.00 & 1.6 & 2.5 \\
\hline & Slope $\left({ }^{\circ}\right)$ & 5.66 & 43.95 & 0.14 & 3.03 & 1.65 & 6.98 & 2.2 & 5.5 \\
\hline & Aspect $\left({ }^{\circ}\right)$ & 188.09 & 359.09 & 0.00 & 184.00 & 99.00 & 290.00 & -0.1 & -1.2 \\
\hline & TWI & 1.00 & 12.58 & 0.00 & 0.00 & 0.00 & 0.95 & 2.7 & 6.2 \\
\hline
\end{tabular}


Table 2. Classification standard of soil available micronutrients in Shanxi Province.

\begin{tabular}{cccccc}
$\begin{array}{c}\text { Micronutrients } \\
\left(\mathrm{mg} \mathrm{kg}^{-1}\right)\end{array}$ & Very low & Low & Medium & High & Very high \\
\hline $\mathrm{Fe}$ & $<2.5$ & $2.5-4.5$ & $4.5-10.0$ & $10.0-20.0$ & $>20.0$ \\
$\mathrm{Mn}$ & $<1.0$ & $1.0-5.0$ & $5.0-15.0$ & $15.0-30.0$ & $>30.0$ \\
$\mathrm{Cu}$ & $<0.1$ & $0.1-0.2$ & $0.2-1.0$ & $1.0-1.8$ & $>1.8$ \\
$\mathrm{Zn}$ & $<0.3$ & $0.3-0.5$ & $0.5-1.0$ & $1.0-3.0$ & $>3.0$ \\
$\mathrm{~B}$ & $<0.2$ & $0.2-0.5$ & $0.5-1.0$ & $1.0-2.0$ & $>2.0$ \\
\hline
\end{tabular}

The Pearson correlation coefficient ( $\mathrm{r}$ ) between micronutrients and chemical parameters, including $\mathrm{pH}$, $\mathrm{SOM}, \mathrm{TN}, \mathrm{AP}$, and AK, or topographic properties, including elevation, slope, topographic wetness index, and aspect, were calculated and are listed in Table 3. Our results showed that those micronutrients, except for $\mathrm{Cu}$, were significantly correlated with $\mathrm{pH}, \mathrm{SOM}$, $\mathrm{TN}, \mathrm{AP}, \mathrm{AK}$, elevation, and slope $(P<0.01)$, and $\mathrm{Cu}$ was correlated with $\mathrm{pH}, \mathrm{AK}$, and aspect $(P<0.05)$. In addition, $\mathrm{Fe}, \mathrm{Mn}$, and $\mathrm{Zn}$ were positively correlated with wetness index $(P<0.05)$.

Table 3. Pearson correlation coefficients ( $\mathrm{r}$ ) of soil available micronutrients with soil chemical and topographic properties in Fanshi County on the Chinese Loess Plateau ( $\mathrm{n}=523)$.

\begin{tabular}{|c|c|c|c|c|c|c|c|c|c|}
\hline Micronutrients & $\mathrm{pH}$ & SOM & $\mathrm{TN}$ & $\mathrm{AP}$ & $\mathrm{AK}$ & Elevation & Slope & Aspect & TWI \\
\hline $\mathrm{Fe}$ & $\overline{0}-30^{* * *}$ & $0.54 * *$ & $0.54 * *$ & $0.41^{* *}$ & $0.33 * *$ & $0.32 * *$ & $0.31 * *$ & -0.07 & $0.10^{*}$ \\
\hline Mn & $\overline{0.25^{* *}}$ & $0.24 * *$ & $0.23 * *$ & $0.17 * *$ & $0.25^{* *}$ & $0.25^{* *}$ & $0.22 * *$ & -0.06 & $0.10^{*}$ \\
\hline $\mathrm{Cu}$ & $-0.10^{*}$ & 0.08 & 0.08 & 0.07 & $0.09 *$ & -0.03 & 0.03 & $-0.10^{*}$ & 0.07 \\
\hline $\mathrm{Zn}$ & $\overline{0.31 * *}$ & $0.35^{* *}$ & $0.37 * *$ & $0.39 * *$ & $0.34 * *$ & $0.29 * *$ & $0.27 * *$ & -0.08 & $0.11^{*}$ \\
\hline B & $\overline{0.14 * *}$ & $0.35 * *$ & $0.34 * *$ & $0.25^{* *}$ & $0.34 * *$ & $0.17^{* *}$ & $0.16^{* *}$ & -0.06 & 0.05 \\
\hline
\end{tabular}

$* P<0.05$. $* * P<0.01$.

\subsection{Spatial analysis of soil available micronutrients}

Semivariances of the micronutrients were fitted well by the exponential model, which was selected over other commonly used models (i.e., spherical, Gaussian, and linear models) because of the minimum mean squared error (Table 4). The geostatistical parameters, including nugget $(\mathrm{C} 0)$, structured variance $(\mathrm{C} 1)$, sill $(\mathrm{C} 0+\mathrm{C} 1)$, and range were obtained. The ratio of nugget to sill, $\mathrm{C} 0 /(\mathrm{C} 0+\mathrm{C} 1)$, was used to characterize the spatial dependency of available micronutrients, which were 56, 31, 61, 66, and 87 for $\mathrm{Fe}, \mathrm{Mn}, \mathrm{Cu}, \mathrm{Zn}$, and $\mathrm{B}$, respectively. A ratio of nugget to sill less than $25 \%$ indicated a strong spatial dependency, a ratio larger than $75 \%$ indicated a weak spatial dependency, and intermediate values indicated that spatial dependency was moderate (Cambardella et al., 1994). This indicated that $\mathrm{Fe}, \mathrm{Mn}, \mathrm{Cu}$, and $\mathrm{Zn}$ had moderate spatial dependency and $\mathrm{B}$ exhibited weak spatial dependency in the watershed. 
The interpolation maps were obtained based on the theoretical semivariance models (Figure 3). The spatial distributions of $\mathrm{Mn}$ and $\mathrm{Zn}$ were similar. According to the micronutrient distribution, there was a zone with lower values for all micronutrients, except for $\mathrm{Cu}$, in the middle of the watershed between the northern and southern areas. This zonal distribution may be affected by topographic factors, because it appeared similar to the landscape distribution.

Table 4. Geostatistical summary of the content of soil available micronutrients.

\begin{tabular}{ccccccc}
\hline Micronutrients & $\begin{array}{c}\text { Nugget } \\
\left(\mathrm{mg} \mathrm{kg}^{-1}\right)\end{array}$ & $\begin{array}{c}\text { Sill } \\
\left(\mathrm{mg} \mathrm{kg}^{-1}\right)\end{array}$ & $\begin{array}{c}\text { Range } \\
(\mathrm{m})\end{array}$ & $\begin{array}{c}\text { Nugget/Sill } \\
(\%)\end{array}$ & $\begin{array}{c}\text { MSE } \\
\left(\mathrm{mg} \mathrm{kg}^{-1}\right)\end{array}$ & $\mathrm{R}^{2}$ \\
\hline $\mathrm{Fe}$ & 10.2 & 18.1 & 4103 & 56 & 0.04 & 0.73 \\
$\mathrm{Mn}$ & 9.1 & 29.2 & 9400 & 31 & 0.08 & 0.78 \\
$\mathrm{Cu}$ & 0.3 & 0.5 & 18340 & 61 & 0.02 & 0.75 \\
$\mathrm{Zn}$ & 0.2 & 0.4 & 3796 & 66 & 0.02 & 0.67 \\
$\mathrm{~B}$ & 0.1 & 0.1 & 8519 & 87 & 0.01 & 0.62 \\
\hline
\end{tabular}

MSE refers to mean standardized error.

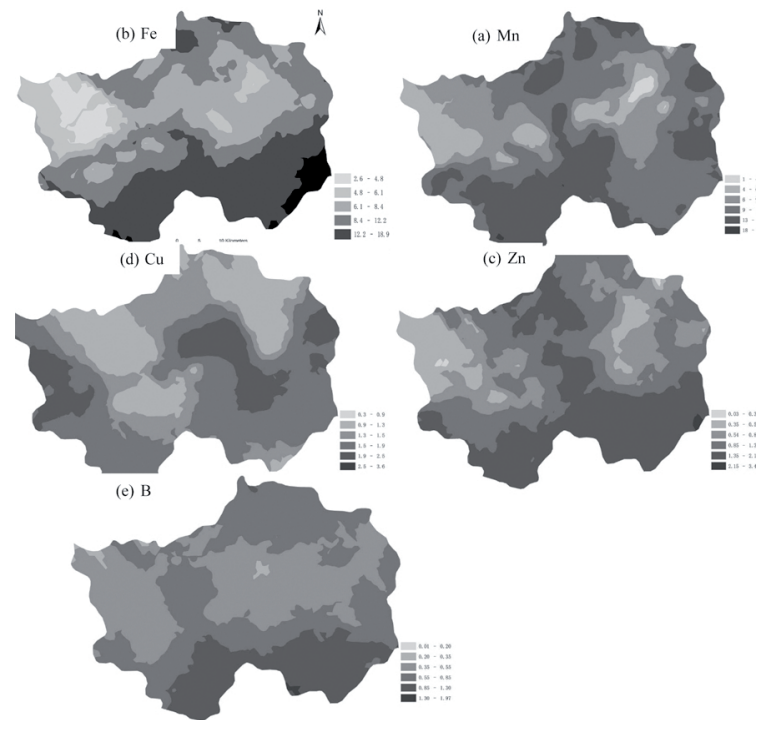

Figure 3. Interpolated maps of (a) Fe, (b) $\mathrm{Mn}$, (c) $\mathrm{Cu}$, (d) $\mathrm{Zn}$, and (e) B by ordinary Kriging regression. The units for the micronutrients was $\mathrm{mgkg}^{-1}$.

\subsection{Effects of observed variables on latent variables} of soil chemistry and topography

To obtain good fitting models while avoiding excessive parameters, Modification Indices (MIs) were used to include the residual covariance for MI values larger than 4, and the models with lowest Akaike Information Criterion (AIC) values for $\mathrm{Fe}, \mathrm{Mn}, \mathrm{Cu}$, $\mathrm{Zn}$, and $\mathrm{B}$ were selected. The parameters of the fitting SEM are shown in Table 5. The AIC values for the good fitting models of $\mathrm{Fe}, \mathrm{Mn}, \mathrm{Cu}, \mathrm{Zn}$, and $\mathrm{B}$ were $74.2,71.6,73.5,65.3$, and 79.6, respectively. 
Table 5. The Goodness-of-Fit parameters of SEMs of $\mathrm{Fe}, \mathrm{Mn}, \mathrm{Cu}$, and B; a good fitting model must satisfy the acceptable values.

\begin{tabular}{ccccccc}
\hline Index & Acceptable & $\mathrm{Fe}$ & $\mathrm{Mn}$ & $\mathrm{Cu}$ & $\mathrm{Zn}$ & $\mathrm{B}$ \\
\hline$P$-value & $>0.05$ & 0.17 & 0.27 & 0.20 & 0.16 & 0.16 \\
$\chi^{2}$ & - & 28.05 & 25.60 & 27.45 & 27.29 & 33.63 \\
df & - & 22 & 22 & 22 & 17 & 22 \\
$\chi^{2} / \mathrm{df}$ & $<3.00$ & 1.28 & 1.16 & 1.25 & 1.61 & 1.53 \\
GFI & $>0.95$ & 0.99 & 0.99 & 0.99 & 0.99 & 0.99 \\
NFI & $>0.95$ & 0.99 & 0.99 & 0.99 & 0.99 & 0.99 \\
CFI & $>0.95$ & 1.00 & 1.00 & 1.00 & 1.00 & 1.00 \\
RMR & $<0.05$ & 0.00 & 0.00 & 0.00 & 0.00 & 0.00 \\
RMSEA & $<0.06$ & 0.02 & 0.02 & 0.02 & 0.03 & 0.03 \\
AIC & - & 74.16 & 71.60 & 73.45 & 65.29 & 79.63 \\
\hline
\end{tabular}

The structure of SEM and the specific parameters in the model were tested by the chi-square $\left(\chi^{2}\right)$ test. A non-significant $P$ value of the established model indicated that the model structure and data structure do not differ significantly. Hence, the model might accurately represent the relationships among the variables. In our study, the $P$ values were not significant for $\mathrm{Fe}(P=0.17), \mathrm{Mn}(P=0.27), \mathrm{Cu}$ $(P=0.20), \mathrm{Zn}(P=0.16)$, and $\mathrm{B}(P=0.16)$, supporting the established models (Table 5). Additionally, a ratio of $\chi^{2}$ to the degrees of freedom ( $d f$ ) being less than 3 , indicates that the structure and parameters of the model were satisfactory (Hoe, 2008). The $\chi^{2}$ to the $\mathrm{df}$ values for $\mathrm{Fe}, \mathrm{Mn}, \mathrm{Cu}, \mathrm{Zn}$ and $\mathrm{B}$ were $1.28,1.16,1.25,1.61$ and 1.53 , respectively, which suggested the acceptability of the models. Other indices, including Goodness-of-Fit Index (GFI), Normed Fit Index (NFI), Comparative Fit Index (CFI), Root Mean square Residual (RMR), and Root Mean Square Error of Approximation (RMSEA), are also often used to evaluate the fitness of models. We applied these indices to our data, and the calculated values of GFI, NFI, CFI, and RMR were $0.99,0.99,1.00,0.00$, respectively, and a RMSEA value was 0.02 or 0.03 . All values were in the acceptable interval (GFI, NFI, CFI $>0.95$, $\mathrm{RMR}<0.05$, and RMSEA $<0.06$ ), further demonstrating the soundness of the models.

The final SEMs are presented in Figure 4. Standardized path coefficients (SPCs) were used to evaluate the strength of direct effect between the latent variables. The latent variable of soil chemistry was related to $\mathrm{pH}, \mathrm{SOM}, \mathrm{TN}, \mathrm{AP}$, and $\mathrm{AK}$, with corresponding SPCs of $0.97,0.99,0.98,0.56$, and 0.57 , respectively (Figure 4). Contributions of $\mathrm{pH}$, $\mathrm{SOM}$, and TN to the latent variable of soil chemistry were similar, while the contributions of AP and AK were similar.

The latent variable of topography was significantly correlated with elevation, slope, aspect, and wetness index, and corresponding SPCs value were $0.83,0.74,0.51$, and 0.52 , respectively. Contributions of both elevation and slope to the latent variable of topography were identical, while the contributions of aspect and wetness index weresimilar. In addition, there was a constant correlation between soil chemistry and topography (SPC was 0.44 ), which indicated a direct effect of topography to soil chemistryof 0.44 . 

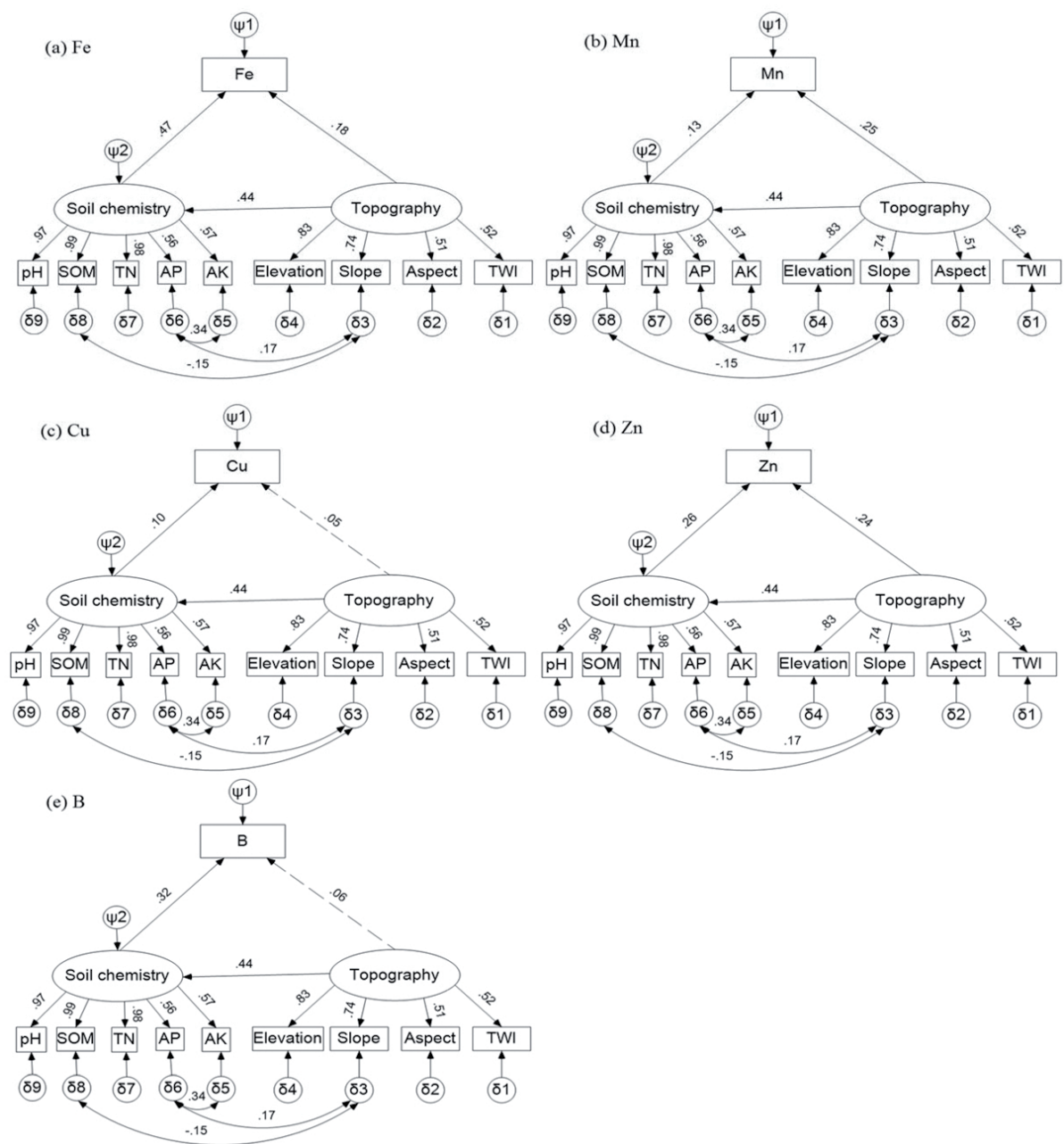

Figure 4. Model results for (a) Fe, (b) Mn, (c) Cu, (d) Zn, and (e) B. Single arrows represent the direct pathway of one variable to another, and double arrows represent the correlation between two variables. Solid arrows represent significant pathways and dotted arrows represent non-significant pathways. The standardized path coefficients (SPCs) are listed beside the lines.

\subsection{Effects of soil chemistry and topography on soil available micronutrients}

In the model for available $\mathrm{Fe}$, the direct pathways from topography to $\mathrm{Fe}$ and from soil chemistry to $\mathrm{Fe}$ were statistically significant (Figure 4a).
Additionally, the indirect pathway from topography via soil chemistry to Fe was also significant. The total effect of soil chemistry to $\mathrm{Fe}(0.47)$ was greater than the effect of topography (0.39; Table 6).The SEM of Fe explained $25 \%$ of the variation in Fe. 
Table 6. Standardized direct, indirect, and total (including both direct and indirect) effects of soil chemistry and topography on micronutrients.

\begin{tabular}{lcccc}
\hline & Total & Direct & Indirect & Variation explained (\%) \\
\hline Fe $\leftarrow$ & & & & 25 \\
Topography & 0.39 & 0.18 & 0.21 & \\
$\begin{array}{l}\text { Soil chemistry } \\
\text { Mn } \leftarrow\end{array}$ & 0.47 & 0.47 & 0.00 & 8 \\
$\begin{array}{l}\text { Topography } \\
\text { Soil chemistry }\end{array}$ & 0.31 & 0.25 & 0.06 & \\
Cu $\leftarrow$ & 0.13 & 0.13 & 0.00 & 1 \\
Topography & 0.00 & 0.05 & 0.05 & \\
$\begin{array}{l}\text { Soil chemistry } \\
\text { Zn } \leftarrow\end{array}$ & 0.10 & 0.10 & 0.00 & 13 \\
Topography & 0.35 & 0.24 & 0.11 & \\
Soil chemistry & 0.26 & 0.26 & 0.00 & \\
B $\leftarrow$ & & & & \\
Topography & 0.21 & 0.06 & 0.15 & \\
Soil chemistry & 0.32 & 0.32 & 0.00 & \\
\hline & & & & \\
& & & \\
\end{tabular}

$\leftarrow$ represents the effects of other variables on it.

For $\mathrm{Mn}$, the direct pathways from topography and soil chemistry were statistically significant, and the indirect effect from topography via soil chemistry was 0.06 (Figure 4b). Correlations between $\mathrm{Mn}$ and topography or soil chemistry were significantly positive, and total effects of both factors onMn were 0.31 and 0.13 , respectively (Table 6). However, the SEM only explained $8 \%$ of the variation of $\mathrm{Mn}$.

For $\mathrm{Cu}$, the direct pathway from topography was not significant, but the direct pathway from soil chemistry was significant $(P<0.05$; Figure $4 \mathrm{c})$. The indirect pathway from topography via soil chemistry was insignificant and the SPC was 0.05 . Therefore, the level of $\mathrm{Cu}$ was only directly correlated with soil chemistry. The total effects of topography and soil chemistry on $\mathrm{Cu}$ were 0 and 0.10 (Table 6). The SEM of $\mathrm{Cu}$ accounted for only $1 \%$ of the variation, a much lower value than others.

For $\mathrm{Zn}$, the direct pathways from topography and soil chemistry and indirect pathway from topography via soil chemistry were significant (Figure 4d). Topography and soil chemistry were positively correlated with
$\mathrm{Zn}$. The total effect of topography on $\mathrm{Zn}(0.35)$ was greater than the effect of soil chemistry $(0.26$; Table 6), although the direct effect of soil chemistry was larger than the direct effect of topography. Finally, the SEM of $\mathrm{Zn}$ explained $13 \%$ of the variation in $\mathrm{Zn}$.

For B, the direct pathway from topography was not significant, but the direct pathway from soil chemistry and the indirect pathway from topography via soil chemical properties were both significant (Figure $4 \mathrm{e})$. Additionally, both topography and soil chemistry were positively correlated with B, and the total effects of topography and soil chemistry on B were 0.21 and 0.32 , respectively (Table 6). The SEM of B explained $11 \%$ of the variation in $\mathrm{B}$.

\section{Discussion}

The availability of micronutrients can be affected by many factors. In the present study, the correlation of micronutrient levels and soil chemistry or topography were analyzed by Pearson correlation. The correlation coefficients suggest that the distribution of $\mathrm{Cu}$ was 
different from the distribution of other micronutrients in cultivated land at the watershed scale.

SEM was used to assess the relative effects of soil chemistry and topography on the levels of these micronutrients. The specific parameters of SEM were tested by the chi-square $\left(\chi^{2}\right)$ test. Although the fitting parameters of these SEMs satisfied the acceptable value, the $P$ values were low. According to a previous report, the $\chi^{2}$ test is highly sensitive to sample size, especially for observations larger than 200 (Hooper et al., 2008). In our study, the sample size was 523, which may contribute to the low $P$ values obtained using the $\chi^{2}$ test.

The results of SEM demonstrated that soil chemistry, as determined by the observed variables of SOM, TN, $\mathrm{pH}, \mathrm{AP}$, and $\mathrm{AK}$, significantly affected the distribution of all the micronutrients. Previous studies demonstrated that soil $\mathrm{pH}$ is a major factor that influences the migration and transformation of micronutrients, and soil organic colloids can absorb and accumulate micronutrients (Sharma et al., 2004; Zhao et al., 2012). Additionally, soil nitrogen, phosphorus, and potassium level can affect the availability and distribution of micronutrients (Li et al., 2007). The strength of the effect of soil chemistry on micronutrients was ranked as $\mathrm{Fe}>\mathrm{B}>\mathrm{Zn}>\mathrm{Mn}>\mathrm{Cu}$ according to the determined SPCs.

Topography, which was characterized by elevation, slope, aspect, and topographic wetness index, had a direct effect on soil chemistry and available micronutrients of Mn, Zn, and Fe. Elevation was considered due to its great variability in the study region (ranging from 864 to $2183 \mathrm{~m}$ ) and its influence on microclimate and thus soil-forming processes (Charan et $a l ., 2013)$. Slope is related to soil erosion and deposition processes and affects the distribution of soil horizons. Aspect is related to the amount of solar energy received by the slope and affects plant growth and soil water content which, in turn, influence soil properties (Beguería et al., 2013). A multiple flow direction algorithm was employed to determine the catchment area (Freeman, 1991). The topographic wetness index was derived from the slope and catchment area parameters (Moore et al., 1991), and is related to the soil moisture redistribution in the landscape or soil erosion and accumulation (Chi et al., 2009). Moreover, the strength of the direct effect of topography on micronutrients was ranked as $\mathrm{Mn}>$ $\mathrm{Zn}>\mathrm{Fe}$ according to the calculated SPCs.

Topography also had indirect effects on the availability of Fe, Zn, and B though modifying soil chemistry, and the strength of the indirect effect of topography on micronutrients was ranked as $\mathrm{Fe}>\mathrm{B}>\mathrm{Zn}$. The effect of soil chemistry on Fe was very strong and the effect of topography on Fe was also significant, possibly because the morphology of Fe oxides is related to the topography. The topography exerted more influence on Mn than did soil chemistry. According to previous reports, microclimate and waterlogged conditions can affect the availability of $\mathrm{Mn}$ (Millaleo et al., 2010), which may explain our observed effects of topography on Mn distribution. The direct effects of soil chemistryand topography on $\mathrm{Zn}$ were almost equal. The explanation for this is that $\mathrm{Zn}$ was determined exclusively by adsorption-desorption reactions at $\mathrm{pH}$ below 7 , but precipitationdissolution reactions of $\mathrm{Zn}$ might occur at alkaline pH values (Gerhard et al., 1983), and therefore this procedure could easily be affected by topography. There were no direct effects of topography on $\mathrm{Cu}$ and $\mathrm{B}$ because the moving and leaching amount were very small, especially under high alkaline conditions. However, there was significant indirect effects of topography via soil chemistry on B.

The spatial distribution of available micronutrients, $\mathrm{Zn}$ and $\mathrm{Mn}$ were very similar, possibly due to equivalent effects of topography on these two nutrients. The maps of $\mathrm{Fe}$ and $\mathrm{B}$ were also very similar, possibly due 
to the similar strong effects of soil chemistry. The map of $\mathrm{Cu}$ was different from the others.

The effect of variation of topography and soil chemistry to available micronutrients in SEM were ranked as $\mathrm{Fe}>\mathrm{Zn}>\mathrm{B}>\mathrm{Mn}>\mathrm{Cu}$, with only $1 \%$ for $\mathrm{Cu}$, indicating that only weak effects of soil chemistry and topography on $\mathrm{Cu}$ in this region. It agreed with the different correlation of $\mathrm{Cu}$ with topography or chemistry. The variation of Cumay be related to other influencing factors, such as parent material, soil texture,or farming practices. Further studies should explore the effects of these factors on the available micronutrients in the watershed of the Chinese Loess Plateau.

\section{Conclusions}

In the present study, the relative influences of soil chemistry and topography on the availability of micronutrients ( $\mathrm{Fe}, \mathrm{Mn}, \mathrm{Cu}, \mathrm{Zn}$ and $\mathrm{B}$ ) were investigated by SEM in cultivated land of Fanshi County on the Chinese Loess Plateau. Depending on the SPCs of SEM, the direct effects of soil chemistry on the micronutrients were ranked as $\mathrm{Fe}>\mathrm{B}>\mathrm{Zn}>\mathrm{Mn}>\mathrm{Cu}$, and the direct effects of topography on them were significant except $\mathrm{Cu}$ and $\mathrm{B}$, and were ranked as $\mathrm{Fe}>\mathrm{Zn}$ $>$ Mn. Additionally, topography had a constant direct effect on soil chemistry and had an indirect effect on the micronutrients of $\mathrm{Fe}, \mathrm{Zn}$, and $\mathrm{B}$ via soil chemistry. The study area is a small watershed located in the Chinese Loess Plateau, which occupies $30 \%$ of northern China. Overall, the results obtained from this study can be used to understand the spatial dynamic of soil micronutrients in other locationswith similar landscape. SEM is a direct method that can explore the relative effects of influencing factors on available micronutrients. Therefore, this method has great potential in revealing potential factors affecting soil micronutrients.

\section{Acknowledgements}

This research was supported by the Innovation grant of Shanxi Agriculture University (2014009) and the Shanxi Programs for Science and Technology Development of China (20120311009-1). The authors declared that they have no conflicts of interest to this work.

\section{References}

Angelini, M.E., Heuvelink, G.B.M., Kempen, B., Morrás, H.J.M. 2016. Mapping the soils of an Argentine Pampas region using structural equation modelling. Geoderma. 281, 102-118.

Arhonditsis, G., Stow, C., Steinberg, L., Kenney, M., Lathrop, R., McBride, S., Reckhow, K. 2006. Exploring ecological patterns with structural equation modeling and Bayesian analysis. Ecological Modelling. 192(3), 385-409.

Bao, S. 2008. Soil Agro-chemistrical Analysis. China Agriculture Press (in Chinese), Beijing.

Beaumelle, L., Vile, D., Lamy, I., Vandenbulcke, F., Gimbert, F., Hedde, M. 2016. A structural equation model of soil metal bioavailability to earthworms: confronting causal theory and observations using a laboratory exposure to field-contaminated soils. Science of the Total Environment. 569-570, 961-972.

Beguería, S., Spanu, V., Navas, A., Machín, J., Angulo-Martínez, M. 2013. Modeling the spatial distribution of soil properties by generalized least squares regression: Toward a general theory of spatial variates. Journal of Soil and Water Conservation. $68(3), 172-184$.

Cambardella, C., Moorman, T., Parkin, T., Karlen, D., Novak, J., Turco, R., Konopka, A. 1994. Fieldscale variability of soil properties in central Iowa soils. Soil Science Society of America Journal. 58(5), 1501-1511. 
Charan, G., Bharti, V., Jadhav, S., Kumar, S., Acharya, S., Kumar, P., Gogoi, D., Srivastava, R. 2013. Altitudinal variations in soil physico-chemical properties at cold desert high altitude. Journal of soil science and plant nutrition. 13(2), 267-277.

Chi, B.L., Si, B.C., Walley, F., Yates, T. 2009. Topographic indices and yield variability in a rolling landscape of western Canada. Pedosphere. 19(3), 362-370.

Delgado-Baquerizo, M., García-Palacios, P., Milla, R., Gallardo, A., Maestre, F.T. 2015. Soil characteristics determine soil carbon and nitrogen availability during leaf litter decomposition regardless of litter quality. Soil Biology and Biochemistry. 81, 134-142.

Environmental Monitoring of China 1992. Soil element analysis: modern instrumental techniques. China Environmental Sicence Press (in Chinese), Beijing.

Farooq, M., Wahid, A., Siddique, K.H. 2012. Micronutrient application through seed treatments: a review. Journal of soil science and plant nutrition. 12(1), 125-142.

Freeman, T.G. 1991. Calculating catchment area with divergent flow based on a regular grid. Computers \& Geosciences. 17(3), 413-422.

Gerhard, B., Tiller, K.G., Herms, U., Clayton, P.M. 1983. Adsorption-desorption and/or precipitation-dissolution processes of zinc in soils. Geoderma. 31(4), 337-354.

Hoe, S.L. 2008. Issues and procedures in adopting structural equation modeling technique. Journal of applied quantitative methods. 3(1), 76-83.

Hooper, D., Coughlan, J., Mullen, M.R. 2008. Structural Equation Modelling: Guidelines for Determining Model Fit. Dublin Institute of Technology. 6(1), 141-146.
Hu, W., Si, B.C. 2014. Revealing the relative influence of soil and topographic properties on soil water content distribution at the watershed scale in two sites. Journal of Hydrology. 516, 107-118.

Katyal, J.C., Sharma, B.D. 1991. DTPA-extractable and total $\mathrm{Zn}, \mathrm{Cu}, \mathrm{Mn}$, and $\mathrm{Fe}$ in Indian soils and their association with some soil properties. Geoderma. 49(1-2), 165-179.

Kline, R.B. 1998. Principles and Practice of Structural Equation Modeling. The Guildford Press, New York.

Li, B.Y., Zhou, D.M., Cang, L., Zhang, H.L., Fan, X.H., Qin, S.W. 2007. Soil micronutrient availability to crops as affected by long-term inorganic and organic fertilizer applications. Soil \& Tillage Research. 96(1), 166-173.

Liu, Y., Pan, X., Wang, C., Li, Y., Shi, R. 2016. Can subsurface soil salinity be predicted from surface spectral information? - From the perspective of structural equation modelling. Biosystems Engineering. 152, 138-147.

Millaleo, R., Reyes-Díaz, M., Ivanov, A., Mora, M., Alberdi, M. 2010. Manganese as essential and toxic element for plants: transport, accumulation and resistance mechanisms. Journal of soil science and plant nutrition. 10(4), 470-481.

Moore, I.D., Grayson, R., Ladson, A. 1991. Digital terrain modelling: a review of hydrological, geomorphological, and biological applications. Hydrological processes. 5(1), 3-30.

Nachtergaele, F., Van Velthuizen, H., Verelst, L., Batjes, N., Dijkshoorn, K., Van Engelen, V., Fischer, G., Jones, A., Montanarella, L., Petri, M. 2008. Harmonized world soil database. Food and Agriculture Organization of the United Nations.

Rais, D., Nowack, B., Schulin, R., Luster, J. 2006. Sorption of trace metals by standard and micro suction cups in the absence and presence of dissolved organic carbon. Journal of environmental quality. 35(1), 50-60. 
Sharma, B.D., Harsh, A., Raj, K., Nayyar, V.K. 2004. Relationships Between Soil Characteristics and Total and DTPA-Extractable Micronutrients in Inceptisols of Punjab. Communications in Soil Science \& Plant Analysis. 35(5-6), 799-818.

Shuman, L. 1988. Effect of phosphorus level on extractable micronutrients and their distribution among soil fractions. Soil Science Society of America Journal. 52(1), 136-141.

Sims, J., Patrick, W. 1978. The distribution of micronutrient cations in soil under conditions of varying redox potential and $\mathrm{pH}$. Soil Science Society of America Journal. 42(2), 258-262.

Stephenson, M.T., Holbert, R.L., Zimmerman, R.S. 2006. On the use of structural equation modeling in health communication research. Health Communication. 20(2), 159-167.

Tian, J.1., Huang, C.H. 2000. Soil erosion and dryland farming. CRC press, Florida.
Wang, S.Y., Yu, T., Wang, J.L., Yang, L., Yang, K., Lu, P. 2008. Preliminary Study on Spatial Variability and Distribution of Soil Available Microelements in Pinggu County, Beijing, China. Agricultural Sciences in China. 7(10), 1235-1244.

Yi, Z., Yan, C., Chang-quan, W., Guo-xiang, X. 2012. Characters and Influencing Factors of the Distribution of Cultivated Available Soil Fe, Mn, Cu and $\mathrm{Zn}$ in Xichang City, Sichuan Province, China. Journal of Geography and Geology. 4(2), 115123.

Zhao, H., Xia, B., Chen, F., Zhao, P., Shen, S. 2012. Human health risk from soil heavy metal contamination under different land uses near Dabaoshan Mine, Southern China. Science of the Total Environment. 417-418(7385), 45-54.

Zhu, H., Fu, B., Lv, N., Wang, S., Hou, J. 2014. Multivariate control of root biomass in a semi-arid grassland on the Loess Plateau, China. Plant and Soil. 379(1-2), 315-324. 